\title{
Lyn Kinase Promotes the Proliferation of Malignant Melanoma Cells through Inhibition of Apoptosis and Autophagy via the PI3K/Akt Signaling Pathway
}

\author{
Qianqian Zhang, 1,2,3, Xianguang Meng1, Guojing Qin ${ }^{1}$, Xiaotong Xue1,4, Ningning Dang ${ }^{1}$ \\ 1. Department of Dermatology, Jinan Central Hospital affiliated to Shandong University, Jinan, Shandong Province, China \\ 2. Taishan Medical University, Taian, Shandong Province, China \\ 3. Department of Dermatology, No. 960 Hospital of The Chinese People's Liberation Army, Taian, Shandong Province, China \\ 4. School of Medicine, Shandong University, Jinan, Shandong Province, China \\ $\square$ Corresponding author: Ningning Dang. Address: Department of Dermatology, Jinan Central Hospital affiliated to Shandong University, No.105 Jiefang \\ Road, Jinan 250013, Shandong Province, China. Tel: +86-0531-85695173; Email: dnn1443@zxyy.cn \\ (C) Ivyspring International Publisher. This is an open access article distributed under the terms of the Creative Commons Attribution (CC BY-NC) license \\ (https://creativecommons.org/licenses/by-nc/4.0/). See http://ivyspring.com/terms for full terms and conditions.
}

Received: 2018.08.01; Accepted: 2019.01.05; Published: 2019.01.29

\begin{abstract}
Melanoma is a malignant tumor of cutaneous melanocytes that is characterized by high grade malignancy, rapid progression and high mortality. Thus far, its specific etiological mechanism has been unclear. In this study, we discovered that Lyn kinase expression was up-regulated in melanoma tissues and cells. The function of Lyn was determined by knocking down its expression with a lentivirus containing Lyn shRNA and upregulating its expression with pcDNA3.1-Lyn in the melanoma cell lines M14 and A375. The results showed that Lyn knockdown could significantly inhibit the proliferation, migration and invasiveness through its inhibition of apoptosis and autophagy via the PI3K/Akt pathway in melanoma cell lines. This was further confirmed by treatment with PI3K inhibitor BEZ235. Up-regulation of Lyn promoted the expression of p-Akt and Cyclin D1. Additionally, we investigated the effects of Lyn inhibitor Bafetinib on melanoma cells and the results were consistent with Lyn knockdown. Collectively, our results indicated that Lyn plays a carcinogenic role in multiple cellular functions during melanoma development through regulating apoptosis and autophagy via the PI3K/Akt pathway and may be a valuable potential target for the clinical treatment of melanoma.
\end{abstract}

Key words: Lyn, melanoma, proliferation, autophagy, PI3K/Akt

\section{Introduction}

Melanoma is a malignant tumor that is derived from the skin, mucous membrane, eye and central nervous system. Most malignant melanomas originate from melanocytes in normal skin. It is characterized by high grade malignancy and rapid progression. In the event of metastasis to the blood, melanoma cells can easily spread to all organs of the body. The prognosis once this occurs is poor, with a median survival time of under 1 year and a 5-year survival rate of less than $10 \%$ [1]. Although skin melanoma accounts for approximately $4 \%$ of all skin malignancies, its mortality rate accounts for about $80 \%$ of all mortality from these malignant tumors [2]. Treatment varies depending on the stage of the melanoma. At early stage, it can be treated by surgical methods; however, when regional lymph nodes are involved or in cases of recurrent melanoma, the treatments include palliative surgery, radiotherapy, chemotherapy and targeted therapy, but these methods have limited effects [3].

To date, although studies have shown that the PI3K/Akt [4], Ras/Raf/MEK/ERK [5] and WNT/ $\beta$-catenin [6] pathways participate in the development and progression of melanoma, the specific etiological mechanism of melanoma is still unclear. Therefore, investigation of the molecular mechanism of the pathogenesis of melanoma is a current hotspot in research.

Lyn (v-yes-1 Yamaguchi sarcoma viral related oncogene homolog) located on chromosome 20 at 
locus $8 \mathrm{q} 13$ in humans [7] is a member of the SFKs. SFKs are involved in the modulation and regulation of different processes such as proliferation, differentiation, migration, metabolism and apoptosis [8]. It shares a similar functional homologous region as well as other members of the SFKs [9] and has two splice variants that result in the production of two protein isoforms termed P53 kDa and P56 kDa [7]. Many studies have shown that Lyn is overexpressed and plays a crucial role in many solid tumors, allergic bronchial asthma [10], autoimmune disease [11], Kaposi's Sarcoma [12] and hepatic cirrhosis [13] as well as BCR/ABL kinase inhibitor-resistant CML [14]. However, the role of Lyn in melanoma has not been well-studied. Therefore, Lyn is valuable for analyzing the developmental mechanism of melanoma.

A biochemical analysis of prophase revealed an obvious increase in Lyn expression in 461 cases of cutaneous melanoma compared with 558 normal skin specimens. The results were verified in a melanoma tissue microarray and in cell lines. In the present study, we demonstrated that Lyn plays an oncogenic role in melanoma by its contribution to the regulation of cell proliferation, migration, invasion, apoptosis and autophagy.

\section{Materials and methods}

\section{Immunohistochemistry and evaluation of Lyn staining}

The paraffin-embedded tissue microarray was deparaffinized and rehydrated prior to antigen retrieval. Then, the slide was immersed in the antigen retrieval buffer and heated in the microwave. Soon afterwards, the buffer was allowed to cool to room temperature and was then washed with PBS. Blocking solution was applied to the sections, which were incubated for 1 hour. A primary antibody against Lyn (1:50, Thermo Fisher, USA) was added to the sections prior to incubation at $4^{\circ} \mathrm{C}$ overnight. The second day, the sections were washed three times with PBS for 5 minutes each. An HRP-conjugated secondary antibody was added to the slide, which was further incubated for 2 hours. A diaminobenzidine (DAB; Beyotime, China) kit was used to observe antibody binding. The microarray was first washed and then stained with hematoxylin, and slides were imaged under a microscope (B-150 OPTIKA, Italy). Cases were scored based on the immunostaining intensity $(0$, no staining; 1 , weak staining; 2 , moderate staining; 3 , strong staining) and percentage of positive cells ( 0 , $<5 \% ; 1,5 \%-25 \% ; 2,25 \%-50 \% ; 3,50 \%-75 \% ; 4$, $75 \%-100 \%)$. The final score was calculated by multiplying the above two scores so that the final score ranged from 0 to 12 . We defined final scores of
0-4 as "no or low expression" and 5-12 as "high expression".

\section{Cell lines, reagents and transfection}

The human normal epidermal melanocyte cell line HEM and the human melanoma cell lines M14, A375, and UACC257 were obtained from the Type Culture Collection of the Chinese Academy of Sciences. HEM, M14, A375 and UACC257 cells were cultured in Dulbecco's Modified Eagle Medium (DMEM) supplemented with $10 \%$ fetal bovine serum (FBS), penicillin (100 units/ml), and streptomycin (100 Ag/ml; Invitrogen Corp.) at $37^{\circ} \mathrm{C}$ in a humidified atmosphere with $5 \% \mathrm{CO}_{2}$. The lentivirus containing Lyn shRNA, pcDNA3.1-Lyn vector and pcDNA3.1 vector were purchased from Genechem (Shanghai, China); Bafetinib was purchased from MCE (Monmouth Junction, NJ, USA); and PI3K inhibitor BEZ235 was purchased from Selleckchem (Shanghai, China). The cells were plated in six-well plates and transfection was conducted at $70-80 \%$ confluence.

\section{Western-blot and Antibodies}

The primary antibodies used for the immunoblot analysis were against Lyn (1:500, Thermo Fisher, USA), Akt (1:1000, Cell Signaling Technology, USA), p-Akt (1:1000, Cell Signaling Technology, USA), Cyclin D1 (1:1000, Proteintech, USA), Bcl-2 (1:1000, Proteintech, USA), cleaved-Caspase3 (1:1000, Proteintech, USA), Caspase9 (1:1000, Proteintech, USA), LC3 (1:500, Proteintech, USA), P62 (1:1000, Proteintech, USA), E-cad (1:1000, Proteintech, USA), N-cad (1:1000, Proteintech, USA) and GAPDH (1:3000, Proteintech, USA). The secondary antibodies were anti-rabbit IgG and anti-mouse IgG (1:5000, Proteintech, USA).

M14 and A375 cells were collected and lysed in RIPA buffer ( $140 \mathrm{~mm} \mathrm{NaCl}, 10 \mathrm{~mm}$ Tris $\cdot \mathrm{Cl}, 1 \%$ Triton X-100, 0.1\% sodium deoxycholate, $0.1 \%$ SDS, $1 \mathrm{mM}$ PMSF, plus protease inhibitor mixture, $\mathrm{pH}$ 8.0). Every cell lysate sample was normalized to the total amount of protein $(30 \mu \mathrm{g})$ and was subjected to SDS-PAGE (10\% acrylamide). After SDS-PAGE, the proteins were transferred to PVDF membranes. Membranes were blocked with TBS containing 5\% nonfat milk and $0.1 \%$ Tween-20 for 1 hour at room temperature. Membranes were incubated with the primary antibodies for 2 hours at room temperature, which was followed by three washes in $1 \mathrm{X}$ TBS. The membranes were then incubated with the corresponding secondary antibodies for 1 hour at room temperature, followed by three washes in TBS. The subsequent immunoblot analysis was performed using enhanced chemiluminescence (ECL). The densitometry was measured using ImageJ software, 
and the protein levels were normalized to GAPDH. The assay was repeated three times.

\section{Cell viability and CCK8 proliferation assay}

Melanoma cells were trypsinized and counted to create the suspension. Approximately 2,000 cells were seeded into each well of 96-well plates. Cells were then treated with different concentrations of Bafetinib, and $0.1 \%$ DMSO was used as the control. 24 hours later, cell vitality was detected by adding $10 \mu \mathrm{l}$ of CCK-8 solution (Solarbio, China). After incubation at $37^{\circ} \mathrm{C}$ for 2 hours, the optical density (OD) value of excitation light was detected using a microplate reader (Synergy 2 Multi-Mode Microplate Reader; BioTek, Winooski, VT, USA). Using this information, a suitable concentration was selected for the next study. Every 24 hours for the next three days, $10 \mu \mathrm{l}$ of CCK8 solution was added to each well, and after the cells were cultured for 2 hours, the OD values were measured. The assay was repeated three times.

\section{Colony formation assay}

M14 and A375 cells in the experimental group and the negative control group were seeded into 100 $\mathrm{mm}$ cell culture dishes at a density of 500 cells/well and were cultured for 10 days at $37^{\circ} \mathrm{C}$. Then, the cloned cells were fixed in methanol and stained with $0.5 \%$ crystal violet (in methanol: water, 1:1). The number of colonies containing at least 50 cells was then counted. The data are presented as the mean \pm $\mathrm{SD}$. The assay was repeated three times.

\section{Transwell migration and invasion assays}

The Transwell assay was performed to evaluate cell migration and invasion in a Transwell chamber (Millipore, USA) according to the manufacturer's instructions. First, cells in the different groups were seeded in a chamber at a density of $1 \times 10^{4}$ cells/well and were incubated at $37^{\circ} \mathrm{C}$. After 48 hours, the cells migrated to the lower chamber, at which time they were washed with PBS and stained with crystal violet for $10 \mathrm{~min}$. Finally, the number of cells that had invaded through the membrane was counted and captured by microscopy. The assay was repeated three times.

\section{Statistical analyses}

The data in this study are expressed as the mean \pm SD and were analyzed with SPSS v17.0 (SPSS Inc., Chicago, IL, USA). The Student's t-test was used to determine the significance for all pairwise comparisons of interest.

$\mathrm{P}$ values $<0.05$ were considered statistically significant.

\section{Results}

\section{Lyn expression is up-regulated in human melanoma}

Along with the development of modern gene sequencing technology, an increasing amount of cancer genomics data has been generated, and genome-wide individual genetic analysis is now possible. Here, we assessed Lyn expression using a Gene Expression Profiling Interactive Analysis (GEPIA) [15], which was specifically designed to explore gene expression profiles and to perform interactive analyses using the databases resourced from Genotype-Tissue Expression (GTEx) and the Cancer Genome Atlas (TCGA) [16, 17]. For the expression analysis, the $|\log 2 \mathrm{FC}|$ cutoff was 1 , and the $\log 2(\mathrm{TPM}+1)$ was used as the log-scale. For the prognostic analysis, the group cutoff was the median, and the hazard ratio was calculated based on the Cox PH Model (Figure 1). From the plot, we observed that the expression of Lyn was significantly upregulated in human skin cutaneous melanoma (SKCM) samples compared with that in normal skin tissues.

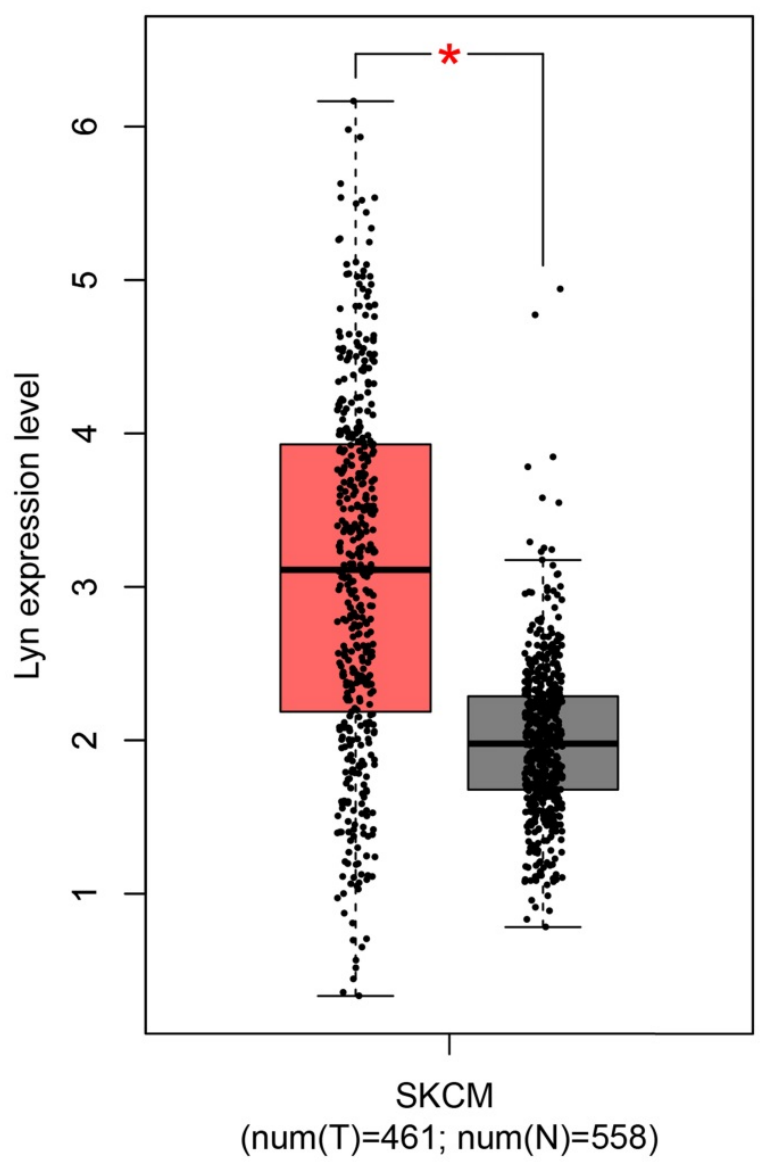

Figure 1: Lyn expression is upregulated in human malignant melanoma. The expression of Lyn was assessed using the GEPIA online database. Lyn expression was significantly increased in SKCM tumor tissues $(n=461$, red box) compared with normal skin tissue ( $n=558$, gray box). $* P<0.05$ by Student's t-test. 
A

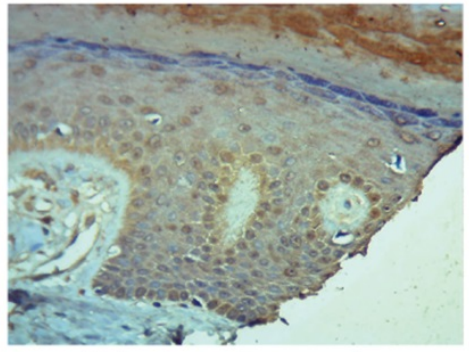

Melmelanocytic nevus tissue

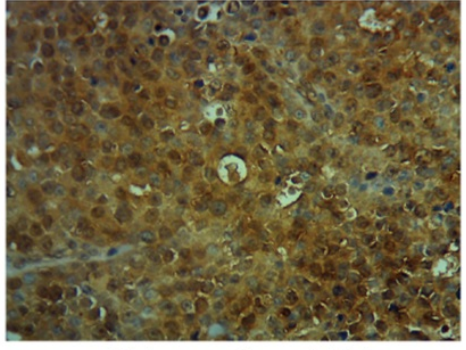

Melanoma tissue(skin)

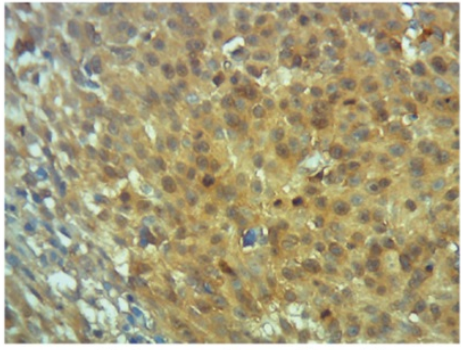

Melanoma tissue(lymph)
B

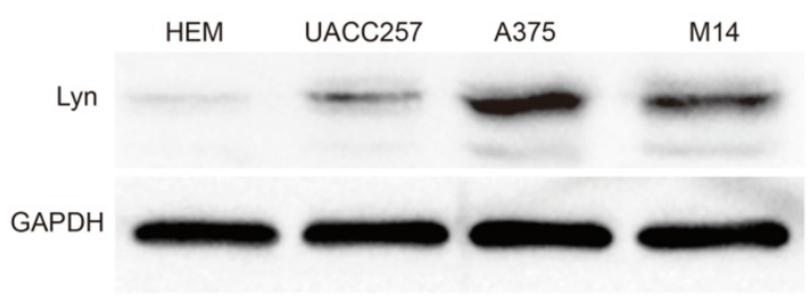

C

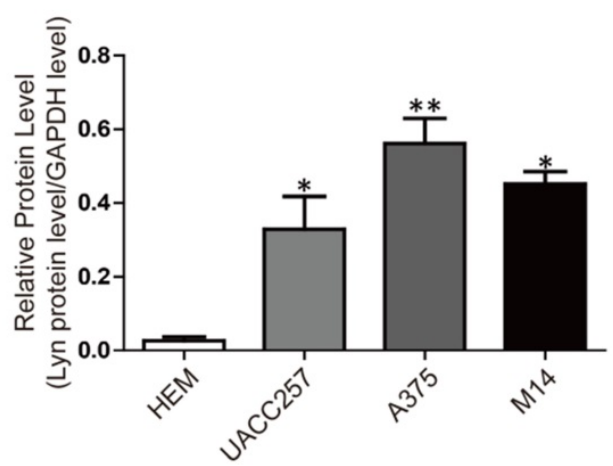

Figure 2: Lyn expression is remarkably increased in melanoma tissues and cells. (A) Immunohistochemical staining for Lyn in melanocytic nevus and melanoma tissues was obtained using an antibody against Lyn (×400). (B) Western blot results revealed that the protein levels of Lyn vary in normal skin cells and different melanoma cell lines. (C) Quantification assay of the intensity of the Lyn bands. Error bars indicate \pm SD. $* P<0.05 ; * * P<0.01$ by Student's t-test. All assays were repeated three times.

\section{Lyn expression is remarkably increased in melanoma tissues and cell lines}

To further confirm the abnormal expression of Lyn in melanoma, we performed immunohistochemistry and Western blot analysis in a tissue microarray and in three cell lines, respectively. The tissue microarray, which contained 8 cases of melanocytic nevus tissue and 40 cases of melanoma tissue, were immunohistochemically stained for the Lyn protein. Compared with melanocytic nevus tissues, strong immunohistochemical staining for Lyn was observed in melanoma tissues, whereas Lyn expression was significantly decreased in melanocytic nevus tissue (Figure 2A).

As shown in Table 1, the expression rate of Lyn in melanoma tissues reached $77.5 \%(31 / 40)$, which is obviously higher than that in normal melanocytes and melanocytic nevus tissues $(25 \%)(2 / 8)(P<0.05)$. In addition, in the analysis of the relationships between Lyn expression and the clinicopathological characteristics of melanoma patients, we found that Lyn expression was significantly correlated with TNM stage and tumor invasion $(P<0.05)$ (Table 2$)$. However, no significant correlation was found between Lyn expression and age or sex.

Next, we examined the expression of Lyn in melanoma cell lines (UACC257, A375, M14) and a normal skin cell line (Human Epidermal Melanocyte,
HEM) as a control by Western blot. Our results showed that the expression level of Lyn was significantly higher in melanoma cells than in HEM cell $(P<0.05)$ (Figure 2B and 2C).

Table 1: The expression of Lyn in melanocytic nevus and melanoma samples

\begin{tabular}{lllll}
\hline Samples & Case $(\mathrm{n})$ & Lyn expression & $\mathrm{P}$ \\
\hline & \multicolumn{5}{l}{ No or Low N $(\mathrm{n} \%)$} & High N $(\mathrm{n} \%)$ & \\
\hline Melanocytic nevus & 8 & $6(75 \%)$ & $2(25 \%)$ & $0.0035^{* *}$ \\
Melanoma & 40 & $9(22.5 \%)$ & $31(77.5 \%)$ & \\
\hline
\end{tabular}

Table 2: Association of Lyn expression with the clinicopathological characteristics of melanoma

\begin{tabular}{|c|c|c|c|c|}
\hline Parameters & $\begin{array}{l}\text { Cases } \\
\text { (n) }\end{array}$ & $\begin{array}{l}\text { Lyn expression } \\
\text { high }\end{array}$ & $\begin{array}{l}\text { Lyn } \\
\text { expression No } \\
\text { or low }\end{array}$ & $\mathrm{P}$-value \\
\hline \multicolumn{5}{|l|}{ Age (years) } \\
\hline$\leq 60$ & 26 & $18(69.23 \%)$ & $8(30.77 \%)$ & 0.08 \\
\hline$>60$ & 14 & $13(92.85 \%)$ & $1(7.14 \%)$ & \\
\hline \multicolumn{5}{|l|}{ Gender } \\
\hline Male & 22 & $17(77.27 \%)$ & $5(22.73 \%)$ & 0.97 \\
\hline Female & 18 & $14(77.78 \%)$ & $4(22.22 \%)$ & \\
\hline \multicolumn{5}{|c|}{$\begin{array}{l}\text { Tumor invasion } \\
\text { (AJCC) }\end{array}$} \\
\hline TI-T3 & 19 & $12(63.16 \%)$ & $7(36.84 \%)$ & $0.03^{*}$ \\
\hline $\mathrm{T} 4$ & 21 & $19(90.47 \%)$ & $2(9.53 \%)$ & \\
\hline \multicolumn{5}{|c|}{$\begin{array}{l}\text { Lymph node } \\
\text { metastasis }\end{array}$} \\
\hline Yes & 12 & $11(91.67 \%)$ & $1(8.33 \%)$ & 0.16 \\
\hline No & 28 & $20(71.43 \%)$ & $8(28.57 \%)$ & \\
\hline \multicolumn{5}{|l|}{ TNM } \\
\hline $\mathrm{I} \sim \mathrm{II}$ & 14 & $8(57.14 \%)$ & $6(42.86 \%)$ & $0.021^{*}$ \\
\hline III $\sim$ IV & 26 & $23(88.46 \%)$ & $3(11.54 \%)$ & \\
\hline
\end{tabular}




\section{Detection of Lyn knockdown efficiency after lentiviral infection of melanoma cell lines}

The melanoma cell lines M14 and A375 were infected with a Lyn knockdown lentivirus, and stable low-expressing cell lines (Lyn-KD) were screened. Analysis of GFP showed that the expression of green fluorescence was clearly increased in Lyn-KD cells compared with negative control cells (NC) for both the M14 and A375 cell lines (Figure 3A and 3B). We further analyzed the different expression levels of Lyn in Lyn-KD and NC cells by Western blot. The results consistently showed that the Lyn knockdown lentivirus could effectively reduce Lyn expression. The differences between the Lyn-KD groups and the NC groups were statistically significant $(P<0.05)$ (Figure 3C).

\section{Lyn knockdown inhibits melanoma cell proliferation}

To investigate the biological functions of Lyn in melanoma progression, the effect of Lyn knockdown on the proliferation of melanoma cell lines was evaluated by CCK8 assay and colony formation assay. From the results of the CCK8 assays, the OD value of Lyn-KD was significantly decreased compared with that in NC cells on days 3 and 4 in M14 and A375 cells $(P<0.05)$ (Figure $4 \mathrm{~A})$. Colony formation assays also confirmed that the number of cell clones was decreased significantly in Lyn-KD cells for both M14 and A375 cells $(P<0.05)$ (Figure 4B). These results suggested that decreased Lyn expression could contribute to the inhibition of proliferation of melanoma cells in vitro.

\section{Lyn knockdown inhibits melanoma cell migration and invasiveness}

To discover more specific effects of Lyn in melanoma cells, Transwell assays were performed to estimate the migration and invasion ability of M14 and A375 cells. Transwell assays \pm Matrigel demonstrated that the number of migrating and invading cells in the Lyn-KD group was significantly less than that in the NC group for both M14 and A375 cells (Figure 5A and 5B). In addition, since epithelial mesenchymal transition (EMT) plays a key role in cell invasion and migration, we further detected the effect of Lyn on the expression of the EMT markers E-cad and N-cad by Western blot. The result showed that E-cad expression was upregulated while $\mathrm{N}$-cad expression was downregulated after infection of M14 and A375 cells with the Lyn knockdown lentivirus ( $P$ $<0.05$ ) (Figure 5C). These results demonstrated that the low expression of Lyn inhibited melanoma cell migration and invasion in vitro.

\section{Analysis of the signaling pathway by which Lyn inhibits apoptosis and autophagy in melanoma cells}

The PI3K/Akt signaling pathway is implicated in a variety of cellular processes, ranging from proliferation to apoptosis and autophagy. To identify the possible underlying mechanism of Lyn's activity
A
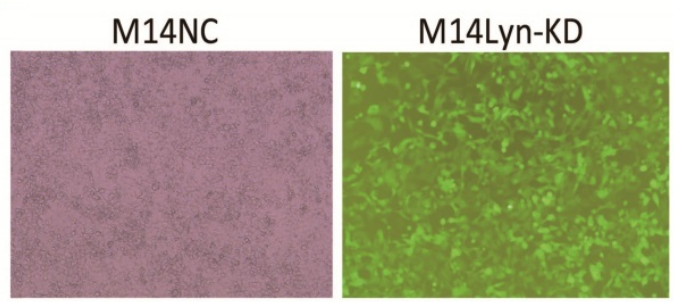

B
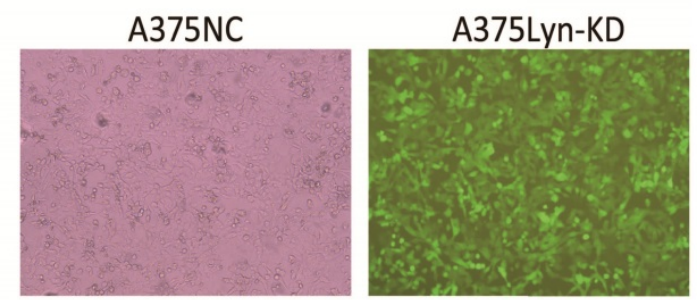

C

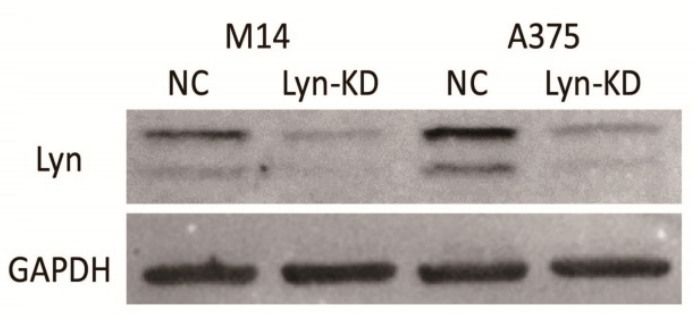

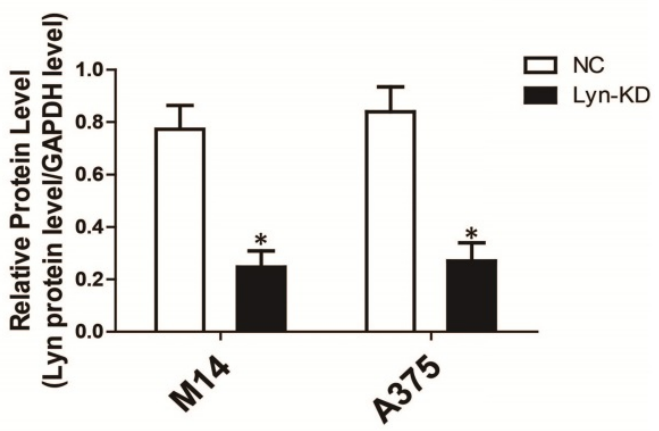

Figure 3: Detection of the transfection efficiency of the lentivirus with Lyn shRNA in melanoma cell lines. (A and B) Fluorescence and bright-field images of M14 and A375 cells after lentiviral transduction (Original magnification: $\times 40$ ). (C) Lyn expression detected by Western blot. Error bars indicate \pm SD. $* P<0.05$ by Student's t-test. All assays were repeated three times. 
in melanoma cells, we analyzed the activity of the PI3K/Akt pathway, as well as the expression of its downstream proteins. Our results revealed that in comparison with NC groups, decreased expression of Lyn resulted in downregulated expression of p-Akt, Cyclin D1, caspase9, Bcl-2 and P62 yet upregulated expression of the cleaved-Caspase3 and LC3-II/I in M14 and A375 cells ( $<0.05)$ (Figure 6A and B). These results indicated that knockdown of Lyn could promote apoptosis and autophagy in melanoma cells in vitro.

BEZ235 is a PI3K inhibitor that reduces the kinase activity of PI3K by competitively binding to its ATP-binding cleft [18]. BEZ235 was used to interfere with the NC and Lyn-KD cells to further validate Lyn's involvement in the PI3K/Akt pathway in melanoma cells. Western blot analysis showed that BEZ235 treatment significantly decreased expression of p-Akt, Cyclin D1, Caspase9, Bcl-2 and P62, but increased expression of cleaved-Caspase3 and LC3-II/I in both NC and Lyn-KD groups of M14 and A375 cells $(\mathrm{P}<0.05)$ (Figure 7A and $\mathrm{B})$. The results demonstrated that BEZ235 further increased apoptosis and autophagy which was induced by the knockdown of Lyn in melanoma cells. These findings are consistent with previous reports regarding BEZ235 causing apoptosis and autophagy in some cell lines $[19,20]$. However, there was no significant difference in expression of the related proteins between the NC and Lyn-KD groups after BEZ235 treatment $(\mathrm{P}>0.05)$ (Figure 7A and $\mathrm{B})$, suggesting that PI3K/Akt pathway activity in melanoma cells was completely blocked. All together, these results indicated that downregulation of Lyn can induce apoptosis and autophagy through the PI3K/Akt signaling pathway in M14 and A375 cells in vitro.

\section{Upregulation of Lyn promotes Cyclin DI via PI3K/Akt signaling pathway for proliferation}

To prove the specificity of shRNA-mediated knockdown of Lyn, the Lyn-KD M14 and A375 cells were both transfected with pcDNA3.1-Lyn (resistant to shRNA) and the expression levels of p-Akt and Cyclin D1 were detected by Western blot. The data demonstrated that the pcDNA3.1-Lyn vector restored the expression of Lyn which were downregulated by

A
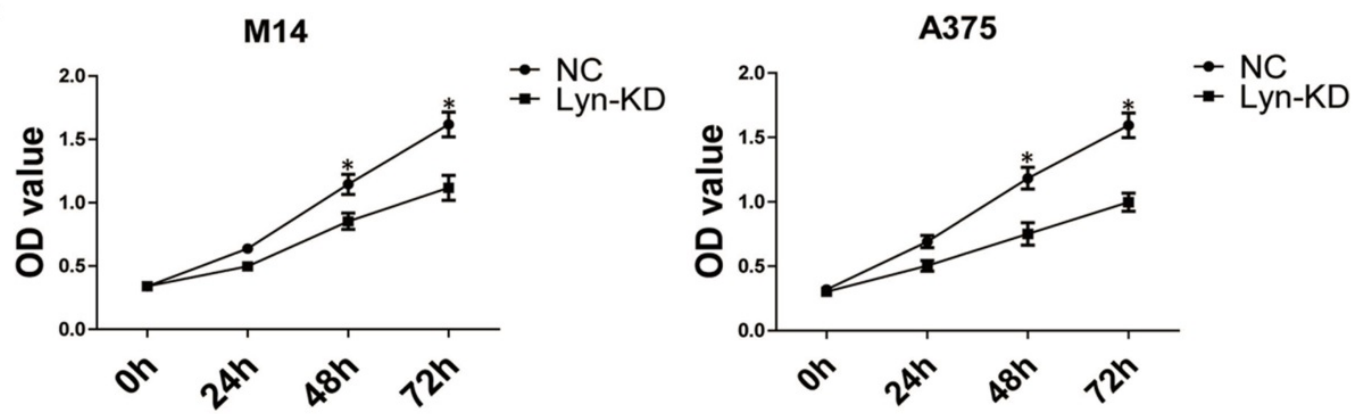

B
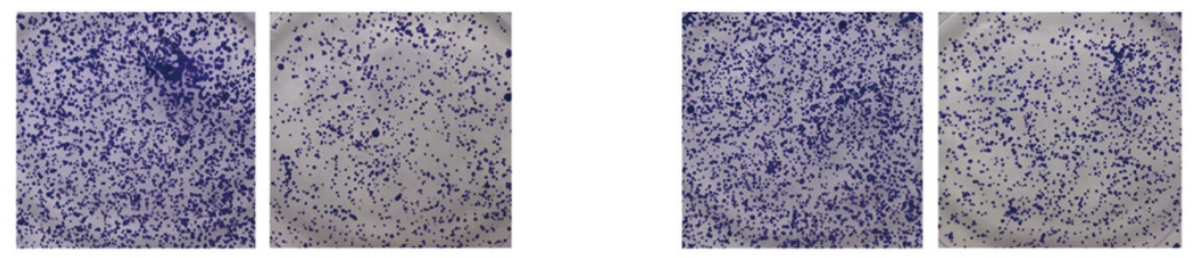

M14NC

M14Lyn-KD

A375NC

A375Lyn-KD
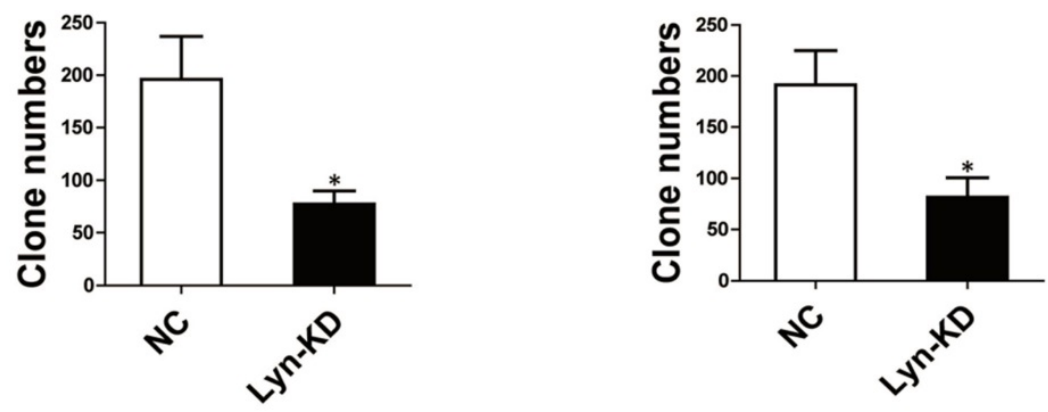

Figure 4: Lyn knockdown significantly inhibits melanoma cell proliferation. (A) Time course curve of the CCK 8 assay results show the changes in the viability of M14 and A375 cells. (B) The number of colony-forming cells was evaluated by colony formation assay. Error bars indicate \pm SD. $* P<0.05$ by Student's $t$-test. All assays were repeated three times. 
lentivirus containing Lyn shRNA and the expression levels of p-Akt and Cyclin D1 were increased ( $\mathrm{P}<$ 0.05) (Figure 8A). In addition, M14 and A375 cells were also transfected with pcDNA3.1-Lyn, and pcDNA3.1 was used as a negative control. The data revealed simultaneous increased expression of Lyn, p-Akt and Cyclin D1 in pcDNA3.1-Lyn transfected cells compared with the NC cells $(\mathrm{P}<0.05)$ (Figure
8B), further demonstrating that overexpression of Lyn can increase the expression of Cyclin D1. Moreover, CCK8 assays showed that transfection of pcDNA-Lyn caused a higher rate of proliferation than the NC group in M14 and A375 cells ( $\mathrm{P}<0.05)$ (Figure 8C). All together, these results confirmed that Lyn promoted cell proliferation through activation of the PI3K/Akt pathway in vitro.
A
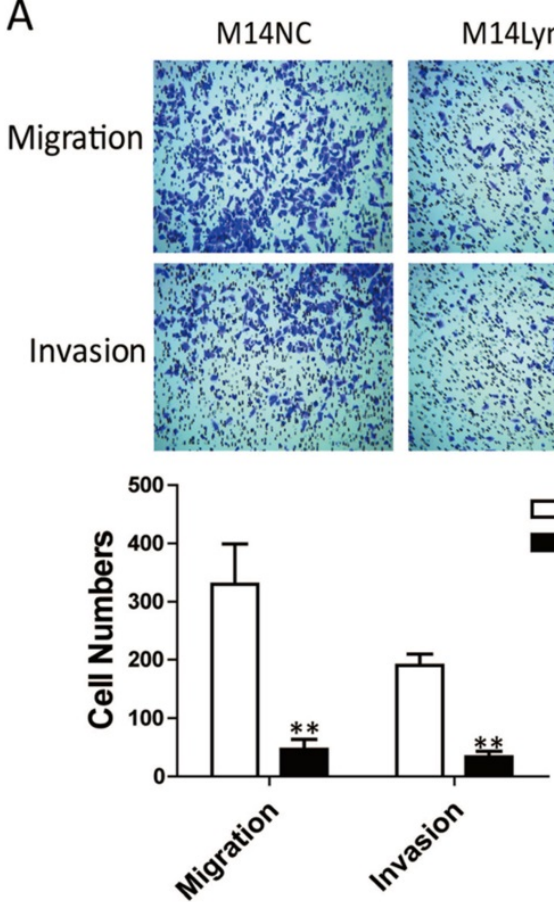

C

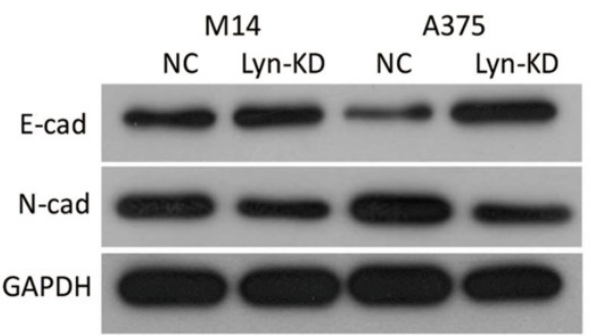

B
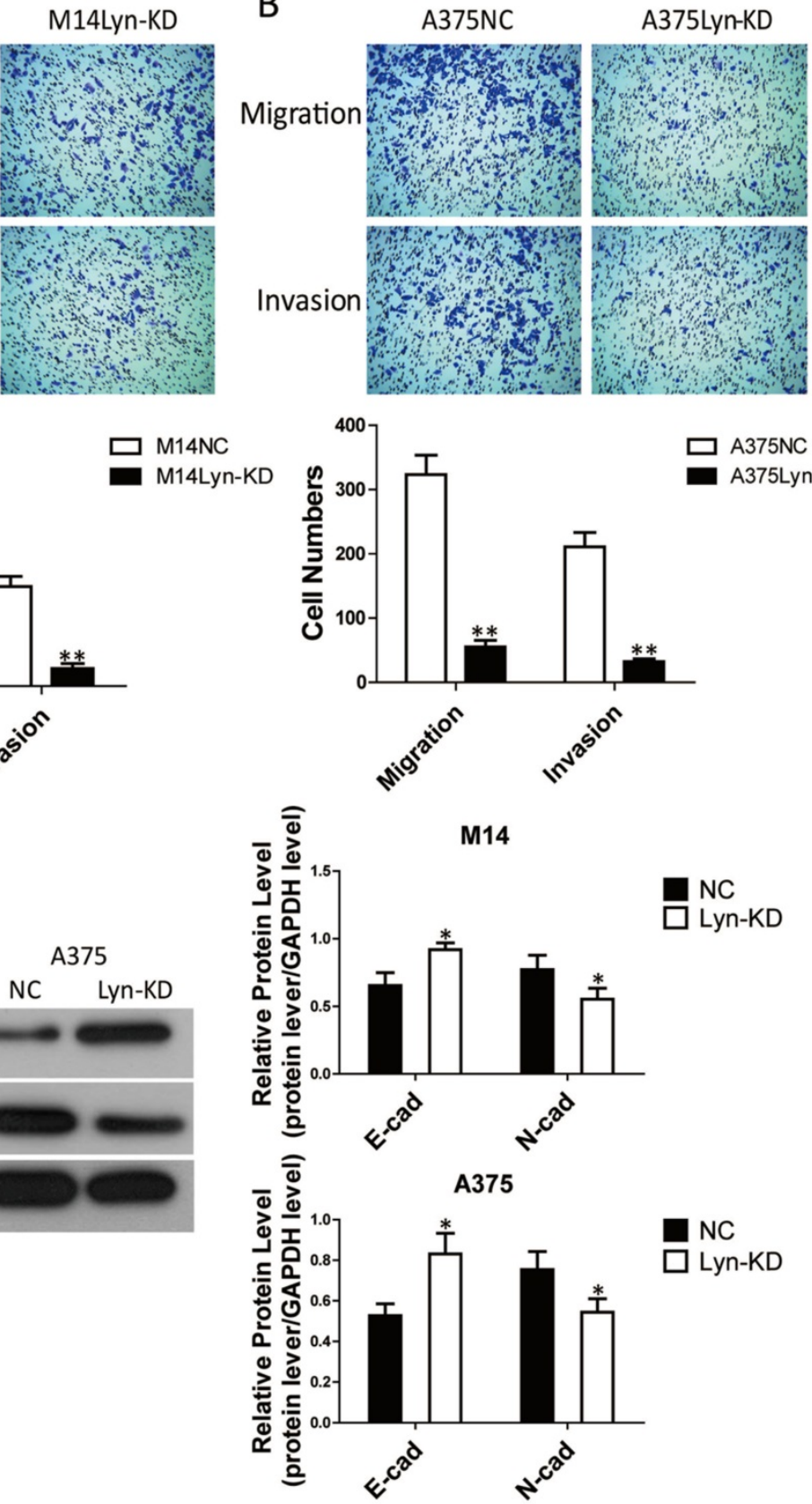

Figure 5: Lyn knockdown significantly inhibits melanoma cell migration and invasion. (A and B) Transwell assays \pm Matrigel were performed in M14 and A375 cells. (C) The effect of Lyn downregulation on the expression of E-cad and N-cad was examined by Western blot. Error bars indicate \pm SD. $* P<0.05$; **P $<0.01$ by Student's t-test. All assays were repeated three times. 
A

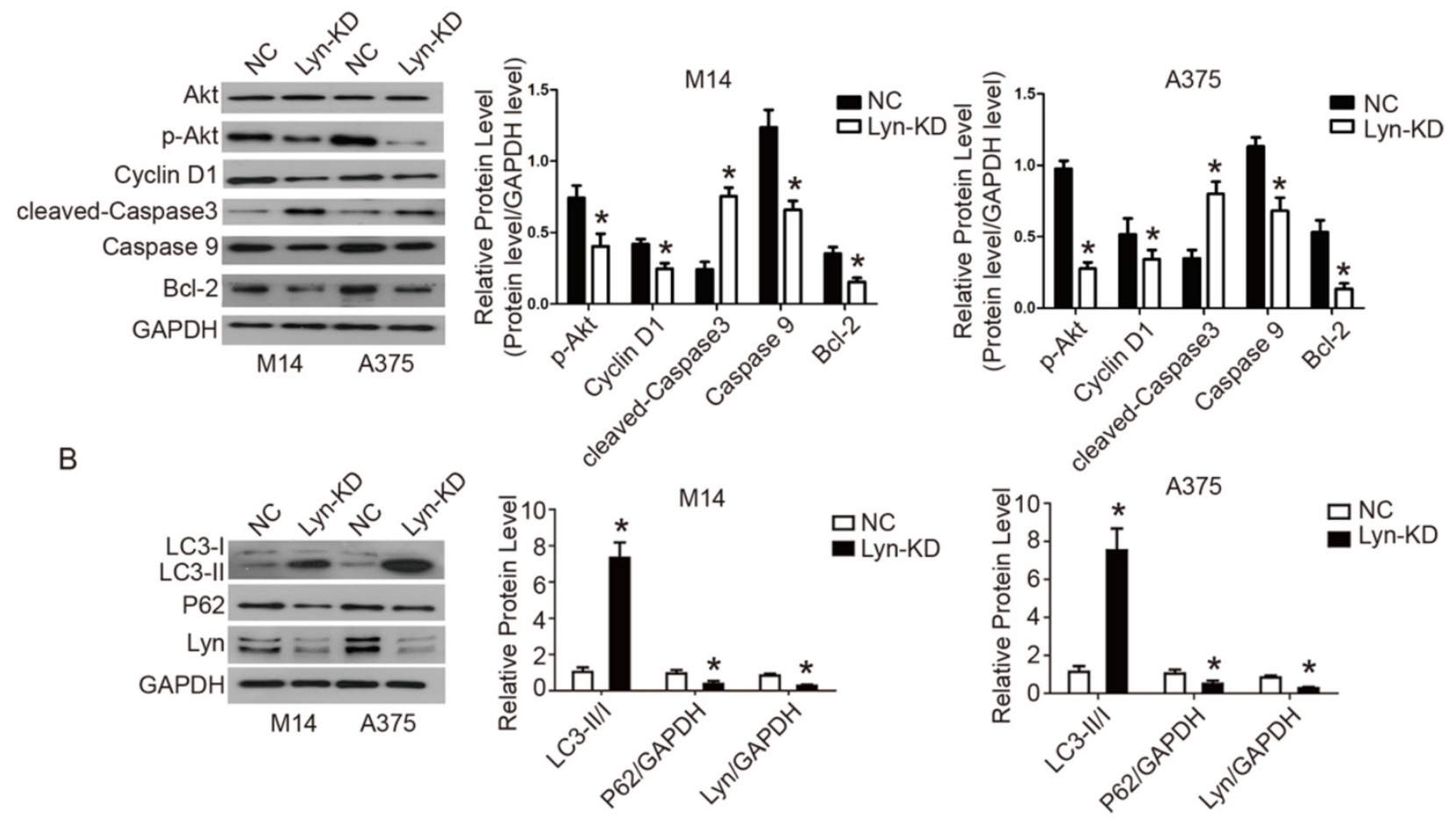

Figure 6: Analysis of the signaling pathway by which Lyn inhibits apoptosis and autophagy in melanoma cells. (Figure $6 \mathrm{~A}$ and B) Western blot results showed the changes of Lyn down-regulation in expression of Akt, p-Akt, Cyclin DI, cleaved-Caspase3, Caspase9, Bcl-2, LC3II/I and P62. (Figure 7 A and B) The expression changes of Lyn, Akt, p-Akt, Cyclin DI, cleaved-Caspase3, Caspase9, Bcl-2, LC3II/I and P62 in Lyn-KD and NC groups for melanoma cell lines M14 and A375 after treatment with PI3K inhibitor BEZ1235 $(1 \mu \mathrm{M})$ determined by Western blot. Error bars indicate \pm SD. $* P<0.05$, N.S. $P>0.05$ by Student's t-test. All assays were repeated three times.

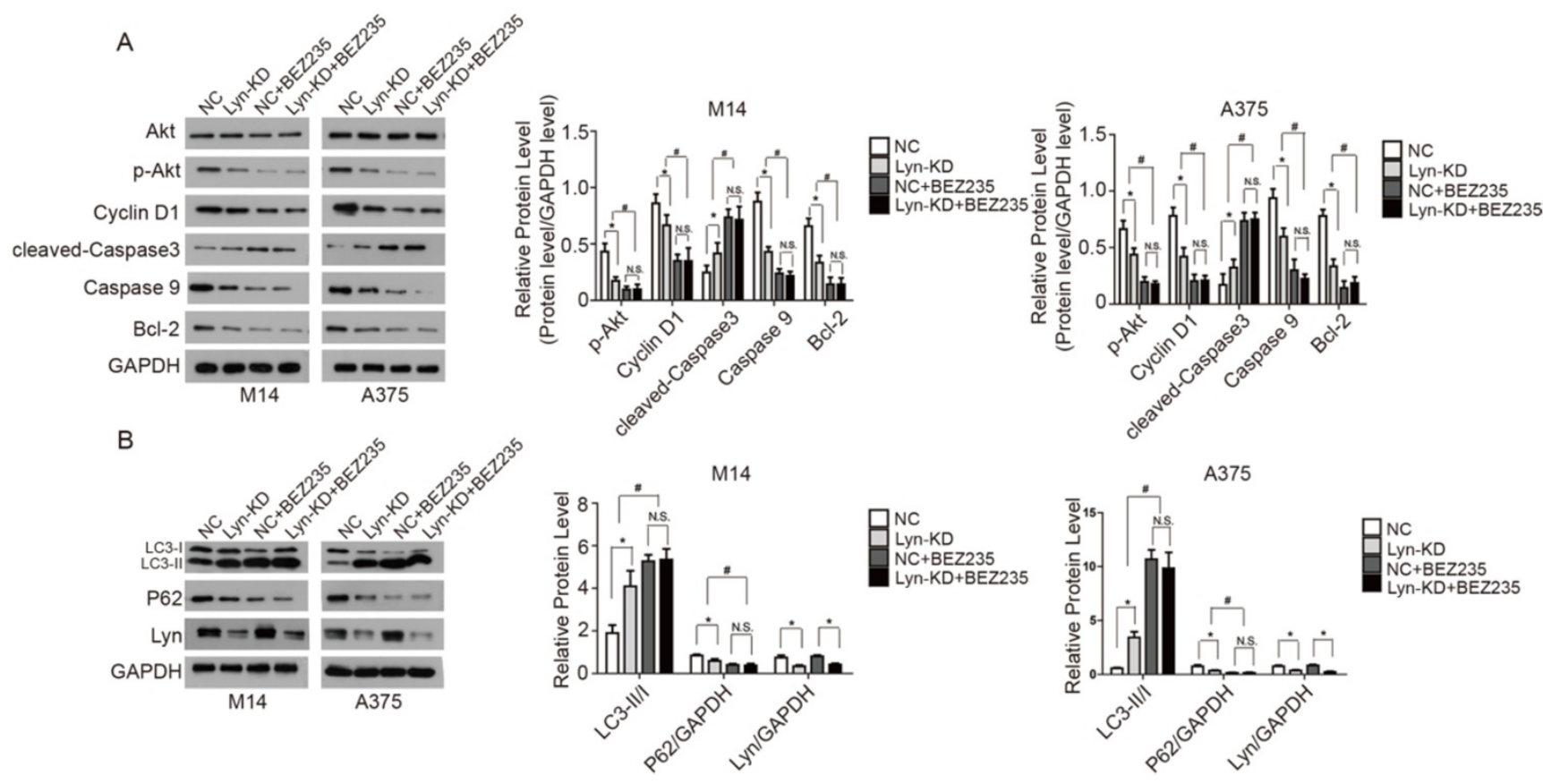

Figure 7: Analysis of the signaling pathway by which Lyn inhibits apoptosis and autophagy in melanoma cells. (Figure $7 \mathrm{~A}$ and $\mathrm{B}$ ) The expression changes of Lyn, Akt, P-Akt, Cyclin D1, cleaved-Caspase3, Caspase9, Bcl-2, LC3II/I and P62 in Lyn-KD and NC groups for melanoma cell lines M14 and A375 after treatment with PI3K inhibitor BEZ1235 $(1 \mu \mathrm{M})$ determined by Western blot. Error bars indicate \pm SD. $* P<0.05$, N.S. $P>0.05$ by Student's t-test. All assays were repeated three times. 
A
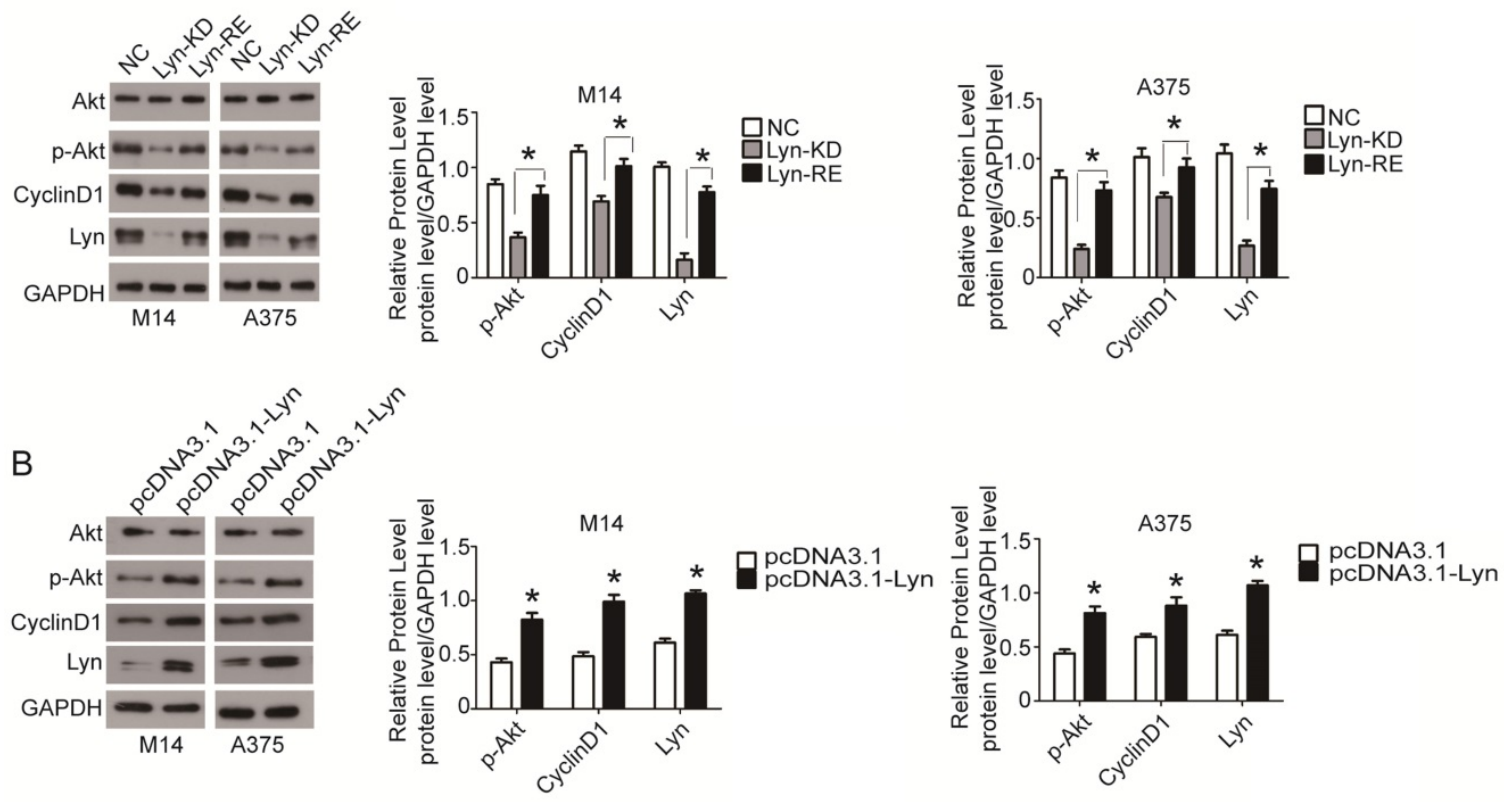

C
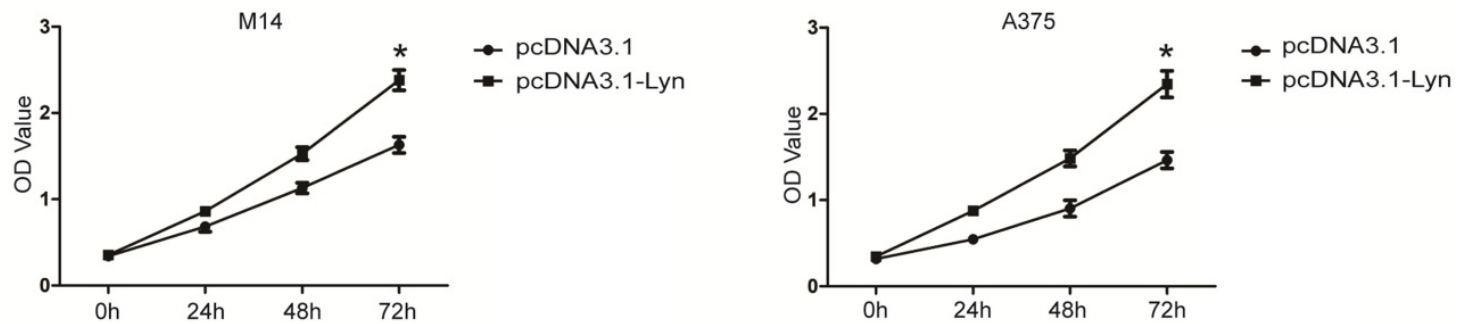

Figure 8: Lyn promotes proliferation of CyclinDI via the PI3k/AKT signaling pathway. (A) Western blot results showed expression changes of Akt, p-Akt and Cyclin DI transfected with pcDNA3.1-Lyn vector in Lyn-KD cells. (B) The effect of Lyn up-regulation on the expression of Akt, p-Akt and Cyclin DI was examined by Western blot. (C) Time course curve of the CCK8 assay results show the changes in viability of M14 and A375 cells. Error bars indicate \pm SD. $* P<0.05$ by Student's t-test. All assays were repeated three times.

\section{Bafetinib inhibits viability, proliferation, migration and invasiveness, while also promoting apoptosis and autophagy in melanoma cells}

Bafetinib, which inhibits Lyn, was added to melanoma cell lines M14 and A375 to observe whether Lyn could be downregulated, thereby affecting cell function changes. We first detected the dose-dependent effects of Bafetinib on melanoma cells. Our results showed that Bafetinib had no effect on cell viability of M14 cells at a concentration lower than $1 \mu \mathrm{M}$. At a concentration of $10 \mu \mathrm{M}$ or higher, Bafetinib had a significant inhibitory effect on the viability of M14 cells compared with the NC cells. Meanwhile, Bafetinib demonstrated a significant inhibitory effect on viability of A375 cells at a concentration of $20 \mu \mathrm{M}$ or higher (Figure 9A). Therefore, we used a concentration of $10 \mu \mathrm{M}$ and $20 \mu \mathrm{M}$ in the rest of the experiments in M14 and A375 cells, respectively.
The effects of Bafetinib on the proliferation of M14 and A375 cells were detected by CCK8 assay. The OD value of excitation light was significantly decreased in both M14 and A375 cells, which were treated with $10 \mu \mathrm{M}$ and $20 \mu \mathrm{M}$ for 24 hours, respectively, compared with the NC cells $(P<0.05)$ (Figure 9B). The clone formation assays showed a much lower number of clones on the Bafetinib treated dishes in both M14 and A375 cells compared to NC cells $(P<0.05)$ (Figure $9 \mathrm{C})$. Transwell assays were used to determine migration and invasion in M14 and A375 cells. The results showed that cell migration and invasion in the Bafetinib-treated groups decreased significantly in both M14 and A375 cells compared to the NC cells $(P<0.05)$ (Figure 9D). Moreover, Western blot showed that Bafetinib treatment decreased the expression of p-Akt, Cyclin D1, cleaved-Caspase3, Bcl-2 and P62, while it simultaneously increased expression of Caspase9 and LC3-II/I in both M14 and A375 cells $(P<0.05)$ (Figure 9E and F). These results, which were consistent with the effects of Lyn 
A $\quad$ B
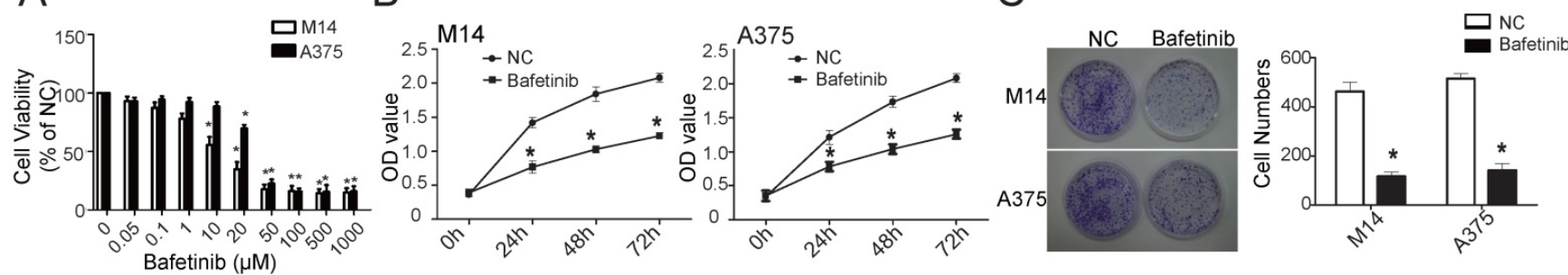

D
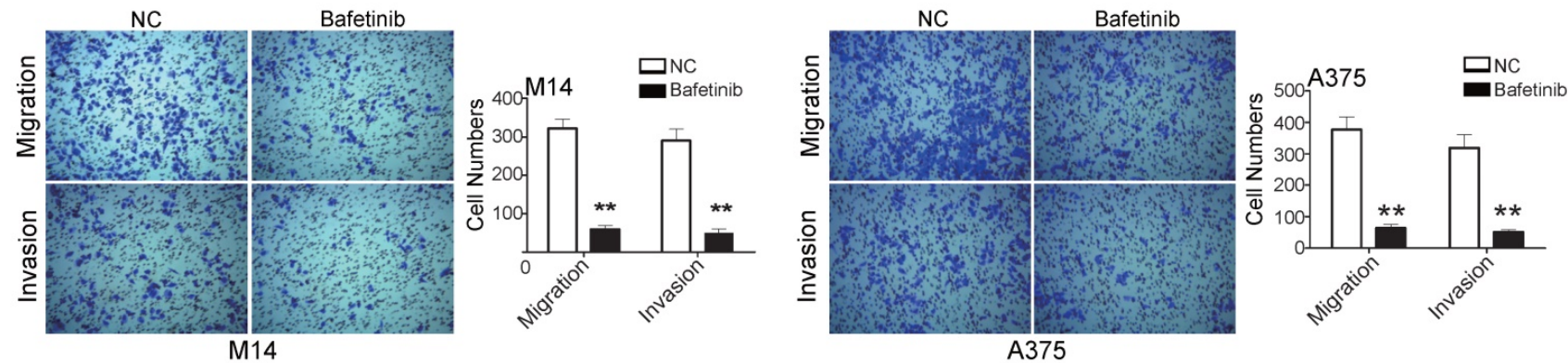

E
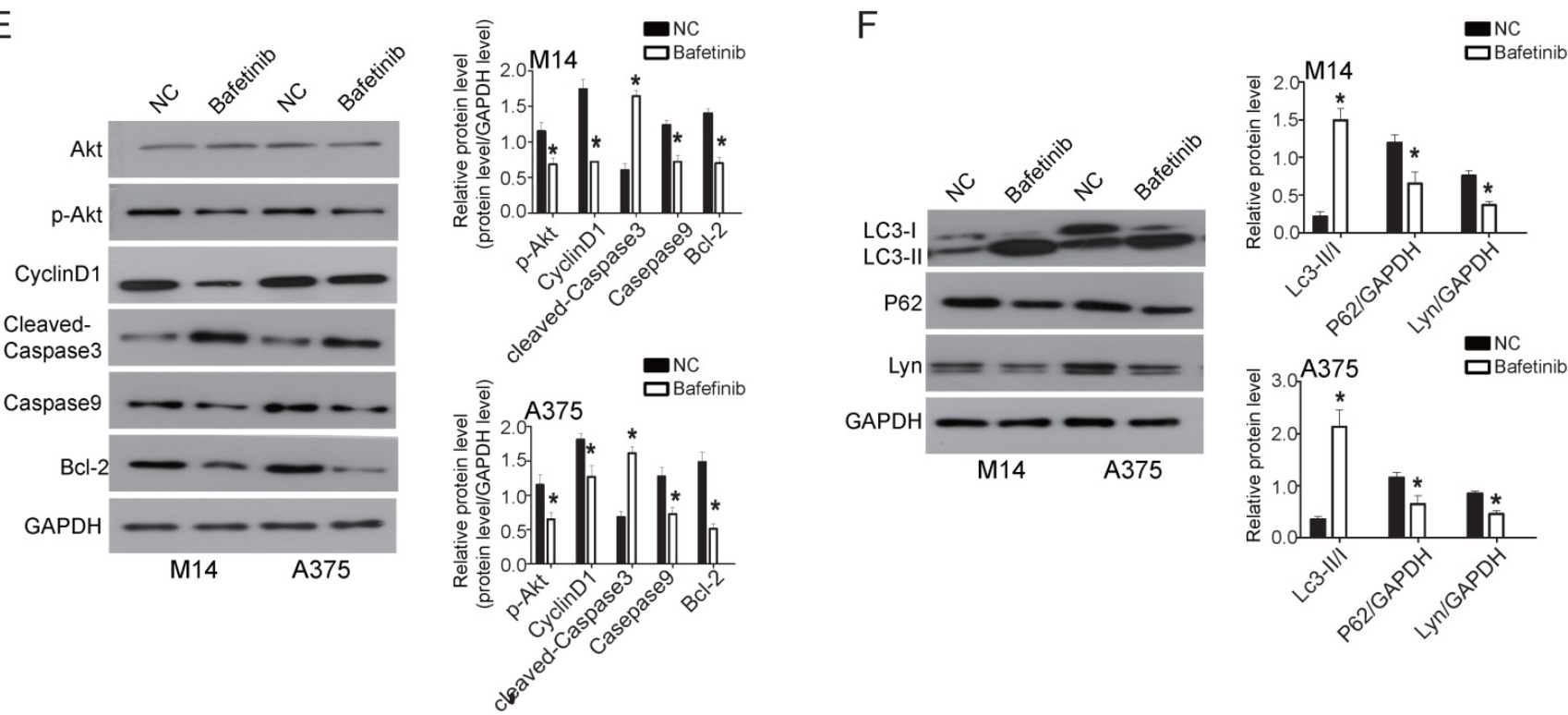

Figure 9: Bafetinib inhibits viability, proliferation, migration and invasiveness while also promoting apoptosis and autophagy in melanoma. (A) The dose-dependent effect of Bafetinib on M14 and A375 cells. Bafetinib has an inhibitory effect on the viability of M14 or A375 cells at both $10 \mu M$ and $20 \mu$ M. (B) CCK 8 assay showed the time course effect of Bafetinib on the viability of M14 and A375 cells. (C) Colony formation assay showed Bafetinib decreased colony formation efficiency of M14 and A375 cells.

(D) Transwell assays demonstrated that Bafetinib treatment decreased cell migration and invasion in M14 and A375 cells. (E and F) Western blot showed the effects of Bafetinib on expression of Akt, p-Akt, Cyclin D1, cleaved-Caspase3, Caspase9, Bcl-2, LC3II/I, P62 and Lyn. Error bars indicate \pm SD. *P < 0.05 by Student's t-test. All assays were repeated three times.

knockdown, demonstrated that Bafetinib inhibited the viability, proliferation, migration and invasion while it also promoted apoptosis and autophagy via the PI3K/Akt pathway of melanoma cells in vitro.

\section{Discussion}

Lyn was the first kinase of the Src family discovered to have dual regulation of signal transduction; it is expressed by most cells in the hematopoietic system, liver, nervous tissue and adipose tissue [21]. Many studies have discovered upregulation of Lyn in numerous tumors and that its activity was closely related to the occurrence and development of tumors, such as colorectal cancer, gastric cancer, renal cell carcinoma, lung cancer, breast cancer, prostate cancer and chronic leukemia [22-27]. A correlation between Lyn expression and drug resistance has also been reported [28, 29]. However, the specific function and precise mechanism of Lyn in tumorigenesis of melanoma 
have not been investigated.

In our present study, we observed that Lyn was significantly overexpressed in melanoma samples compared with melanocytic nevus tissue. Furthermore, we found that the expression of Lyn was associated with TNM stage and tumor invasion of melanoma patients. Western blot showed that Lyn expression was significantly higher in melanoma cells than in HEM cells. These results suggest that Lyn may serve a carcinogenic role in melanoma. The in vitro study showed that Lyn knockdown inhibited the proliferation, migration and invasiveness of melanoma cell lines M14 and A375, further supporting that Lyn is an oncogene in melanoma.

Many studies have shown that several signaling pathways are constitutively activated in melanoma cells. Among them, the PI3K/Akt signaling pathway is activated through multiple mechanisms and plays an important role in melanoma progression [4]. It has also been reported that excessive Lyn activation endowed the invasive power of eosinophils by activating the PI3K/Akt pathway in CEL [30]. Our results showed that knockdown of Lyn inhibited activity of p-Akt as well as the expression of its downstream proteins Cyclin D1, Caspase9, Bcl-2 and P62. Furthermore, Lyn knockdown promoted cleaved-Caspase 3 and LC3-II/I in M14 and A375 cells. These findings indicated that knockdown of Lyn could induce apoptosis and autophagy by inhibiting the PI3K/Akt signaling pathway in melanoma cells in vitro; this was further confirmed by treatment with PI3K inhibitor BEZ235.

In the rescue experiments, transfection with pcDNA3.1-Lyn restored the Lyn expression in Lyn-KD cells, and the expression of p-Akt and Cyclin D1 was also increased at the same time. Furthermore, transfection with pcDNA3.1-Lyn was observed to upregulate the expression of Lyn, p-Akt and Cyclin D1 and to promote proliferation both in M14 and A375 cells. Cyclin D1 which is highly expressed in many cancers including melanoma is one of the downstream components of PI3K/Akt signaling pathway and regulates cell cycle transition from G1 to $S$ phase [31]. Therefore, we can conclude that upregulation of Lyn promotes Cyclin D1 via the PI3k/AKT signaling pathway for proliferation.

Bafetinib is a potent and selective Lyn inhibitor. Previous research has suggested that it could induce programmed cell death through both Caspase-mediated and Caspase-independent pathways in CML cell lines [32]. Morever, Bafetinib directly prevents cell movement, proliferation, and viability induced by chemokines in purified activated stellate cells in vitro [33]. As expected, the effects of Bafetinib treatment with M14 and A375 cells were similar to those of Lyn knockdown, which confirmed that downregulation of Lyn inhibited proliferation, migration and invasion by inducing apoptosis and autophagy through blocking the PI3K/Akt signaling pathway in melanoma cells in vitro.

In conclusion, our biochemical analyses revealed a significant increase in Lyn expression in human melanoma samples, and we demonstrated overexpression of Lyn in melanoma tissues and cells. The knockdown of Lyn and its inhibitor Bafetinib both inhibited proliferation, migration and invasion but also induced autophagy and promoted apoptosis in human melanoma cells via the inhibition of the PI3K/Akt signaling pathway in vitro. Notably, these findings have important preclinical implications and provide a potential target for the clinical treatment of human melanoma.

\section{Acknowledgments}

This study was supported by the China Postdoctoral Science Foundation (CPSF) (No. 2014M550370, 2015T80740) and the Shandong Provincial Natural Science Foundation, China (No. ZR2017MH074).

\section{Competing Interests}

The authors have declared that no competing interest exists.

\section{References}

1. Shah DJ, Dronca RS. Latest advances in chemotherapeutic, targeted, and immune approaches in the treatment of metastatic melanoma. Mayo Clinic Proceedings 2014; 89:504-519.

2. Miller AJ, Jr MM. Melanoma. New England Journal of Medicine 2006; 355:51-65.

3. Bhatia S, Tykodi S, Lee S, Thompson J. Systemic therapy of metastatic melanoma: on the road to cure. Oncology (Williston Park, NY) 2015; 29:126-135.

4. Chen X, Dong H, Liu S, Yu L, Yan D, Yao X, Sun W, Han D, Gao G. Long noncoding RNA MHENCR promotes melanoma progression via regulating miR-425/489-mediated PI3K-Akt pathway. Am J Transl Res 2017; 9:90-102.

5. Inamdar G, Madhunapantula S, Robertson G. Targeting the MAPK pathway in melanoma: why some approaches succeed and other fail. Biochem Pharmacol 2010; 80:624-637.

6. Gajos-Michniewicz A, Czyz M. Modulation of WNT/ $\beta$-catenin pathway in melanoma by biologically active components derived from plants. Fitoterapia 2016; 109:283-292.

7. Xu Y, Harder K, Huntington N, Hibbs M, Tarlinton D. Lyn tyrosine kinase: accentuating the positive and the negative. Immunity $2005 ; 22: 9-18$.

8. Ingley E. Functions of the Lyn tyrosine kinase in health and disease. Cell Communication \& Signaling 2012; 10:21.

9. Boggon T, Eck M. Structure and regulation of Src family kinases. Oncogene 2004; 23:7918-7927

10. Wang X, Yang X, Li Y, Wang X, Zhang Y, Dai X, Niu B, Wu J, Yuan X, Xiong A, et al. Lyn kinase represses mucus hypersecretion by regulating IL-13-induced endoplasmic reticulum stress in asthma. EBioMedicine 2017; 15:137-149.

11. Ban T, Sato G, Nishiyama A, Akiyama A, Takasuna M, Umehara M, Suzuki S, Ichino M, Matsunaga S, Kimura A, et al. Lyn Kinase Suppresses the Transcriptional Activity of IRF5 in the TLR-MyD88 Pathway to Restrain the Development of Autoimmunity. Immunity 2016; 45:319-332.

12. Tan X, Li D, Wang X, Zeng Y, Yan Y, Yang L. Claudin-2 downregulation by KSHV infection is involved in the regulation of endothelial barrier function. J Cutan Pathol 2014; 41:630-639.

13. Li Y, Xiong L, Gong J. Lyn kinase enhanced hepatic fibrosis by modulating the activation of hepatic stellate cells. Am I Transl Res 2017, 9:2865-2877.

14. Kim A, Seong K, Kang H, Park S, Lee S. Inhibition of Lyn is a promising treatment for mantle cell lymphoma with bortezomib resistance. Oncotarget $2015 ; 6: 38225-38238$. 
15. Tang Z, Li C, Kang B, Gao G, Li C, Zhang Z. GEPIA: a web server for cancer and normal gene expression profiling and interactive analyses. Nucleic Acids Research 2017; 45(W1): W98-W102.

16. Consortium G. The Genotype-Tissue Expression (GTEx) project. Nature Genetics 2013; 13:307-308.

17. Tomczak K, Czerwi $\AA$,ska P, Wiznerowicz M. The Cancer Genome Atlas (TCGA): an immeasurable source of knowledge. Contemporary Oncology 2015; 19:68-77.

18. Lin SF, Huang YY, Lin JD, Ting-Chao C, Chuen H, Wong RJ. Utility of a PI3K/mTOR Inhibitor (NVP-BEZ235) for Thyroid Cancer Therapy. Plos One 2012; 7:e46726.

19. Chen L, Jin T, Zhu K, Piao Y, Quan T, Quan C, Lin Z. PI3K/mTOR dual inhibitor BEZ235 and histone deacetylase inhibitor Trichostatin A synergistically exert anti-tumor activity in breast cancer. Oncotarget 2017; 8:11937.

20. Manara MC, Nicoletti G, Zambelli D, Ventura S, Guerzoni C, Landuzzi L, Lollini PL, Maira SM, GarcÃ-aecheverr $\tilde{A}-a$ C, Mercuri M. NVP-BEZ235 as a New Therapeutic Option for Sarcomas. Clinical Cancer Research 2010; 16:530-540.

21. Umemori $\mathrm{H}$, Wanaka $\mathrm{A}$, Kato $\mathrm{H}$, Takeuchi $\mathrm{M}$, Tohyama $\mathrm{M}$, Yamamoto $\mathrm{T}$. Specific expressions of Fyn and Lyn, lymphocyte antigen receptor-associated tyrosine kinases, in the central nervous system. Brain Res Mol Brain Res 1992; 16:303-310.

22. Su N, Peng L, Xia B, Zhao $Y, X u$ A, Wang J, Wang X, Jiang B. Lyn is involved in CD24-induced ERK1/2 activation in colorectal cancer. Mol Cancer 2012; 11:43.

23. Mello A, Leal M, Rey J, Pinto G, Lamarão L, Montenegro R, Alves A, Assumpção P, Borges BN, Smith M, Burbano R. Deregulated Expression of SRC, LYN and CKB Kinases by DNA Methylation and Its Potential Role in Gastric Cancer Invasiveness and Metastasis. PLoS ONE 2015; 10:e140492.

24. Qayyum T, McArdle P, Lamb G, Jordan F, Orange C, Seywright M, Horgan P, Jones R, Oades G, Aitchison M, Edwards J. Expression and prognostic significance of Src family members in renal clear cell carcinoma. Br J Cancer 2012; 107:856-863.

25. Kim YJ, Hong S, Sung M, Park MJ, Jung K, Noh KW, Oh DY, Lee MS, Oh E, Shin YK. LYN expression predicts the response to dasatinib in a subpopulation of lung adenocarcinoma patients. Oncotarget 2016; 7:82876.

26. Elsberger B, Fullerton R, Zino S, Jordan F, Mitchell T, Brunton V, Mallon E, Shiels $\mathrm{P}$, Edwards J. Breast cancer patients' clinical outcome measures are associated with Src kinase family member expression. Br J Cancer 2010; 103:899-909.

27. Zardan A, Nip K, Thaper D, Toren P, Vahid S, Beraldi E, Fazli L, Lamoureux F, Gust K, Cox M, et al. Lyn tyrosine kinase regulates androgen receptor expression and activity in castrate-resistant prostate cancer. Oncogenesis 2014; 3:e115.

28. Wu J, Meng F, Lu H, Kong L, Bornmann W, Peng Z, Talpaz M, Donato N. Lyn regulates BCR-ABL and Gab2 tyrosine phosphorylation and $\mathrm{c}-\mathrm{Cbl}$ protein stability in imatinib-resistant chronic myelogenous leukemia cells. Blood 2008; 111:3821-3829.

29. Tabariès S, Annis M, Hsu B, Tam C, Savage P, Park M, Siegel P. Lyn modulates Claudin-2 expression and is a therapeutic target for breast cancer liver metastasis. Oncotarget 2015; 6:9476-9487.

30. Li B, Zhang G, Li C, Li R, Lu J, He Z, Wang Q, Peng Z, Wang J, Dong Y. Lyn mediates FIP1L1-PDGFRA signal pathway facilitating IL-5RA intracellular signal through FIP1L1-PDGFRA/JAK2/Lyn/Akt network complex in CEL. Oncotarget 2017; 8:64984-64998.

31. Qie S, Diehl JA. Cyclin D1, Cancer Progression and Opportunities in Cancer Treatment. Journal of Molecular Medicine 2016; 94:1-14.

32. Santos FP, Kantarjian H, Cortes J, Quintas-Cardama A. Bafetinib, a dual $\mathrm{Bcr}-\mathrm{Abl} / \mathrm{Lyn}$ tyrosine kinase inhibitor for the potential treatment of leukemia. Current Opinion in Investigational Drugs 2010; 11:1450-1465.

33. Hung P, Chiara B, Chintan C, Yang W, Rodriguez MD, Liu ST, Gabriele G, Lewis MS, Vincenzo C, Pandol SJ. Essential Role of Lyn in Fibrosis. Frontiers in Physiology 2016; 7: 387. 